\title{
Explorando la Variabilidad Petrográfica entre Vasijas Decoradas y Lisas del Sitio La Palmera 2 (Entre Ríos, Argentina): Hacia un Abordaje Microscópico del Arte Cerámico Prehispánico de la Cuenca del Río Paraná
}

\author{
Exploring the Petrographic Variability between Decorated and Plain Vessels of La \\ Palmera 2 Site (Entre Rios, Argentina): Toward a Microscopic Approach of the Pre- \\ Hispanic Ceramic Art of the Paraná River Basin
}

Flavia V. Ottalagano ${ }^{\mathrm{i}}$

\begin{abstract}
RESUMEN
Este trabajo explora la variabilidad petrográfica de un conjunto cerámico procedente de las tierras bajas del Paraná medio: específicamente del sitio La Palmera 2 (provincia de Entre Ríos, Argentina), con la finalidad de abordar aspectos tecnológicos del arte alfarero de las sociedades que habitaron la región durante el Holoceno tardío. Se ofrece una propuesta de estudio en la que se consideran comparativamente muestras de vasijas lisas y decoradas con distintas técnicas: pintura roja, incisión y modelado zoomorfo. Se analizan asimismo cortes delgados correspondientes a "alfarerías gruesas" o "campanas", artefactos peculiares de la arqueología del río Paraná. Los resultados señalan una ausencia de diferencias petrográficas significativas entre las muestras analizadas, sugiriendo que los alfareros aplicaron elecciones técnicas similares para la manufactura de vasijas lisas y decoradas. Al mismo tiempo, se detectan algunas características petrográficas específicas en las "alfarerías gruesas", indicando la implementación de elecciones tecnológicas particulares para la elaboración de estos artefactos.
\end{abstract}

Palabras clave: Análisis Petrográfico, Arte Alfarero, Cuenca Del Paraná Medio, Holoceno Tardío.

\section{ABSTRACT}

This paper explores the petrographic variability of a ceramic assemblage from the lowlands of the middle Paraná: specifically from La Palmera 2 site (province of Entre Rios, Argentina), with the aim of approaching technological aspects of the pottery art of the societies that inhabited the region during the Late Holocene. We offer a study proposal in which we comparatively consider samples of plain vessels and decorated vessels, with different techniques: red paint, incision and zoomorphic modeling. Likewise, we analyze thin sections corresponding to "coarse ware" or "campanas", devices peculiar to the archeology of the Paraná River. The results point out a lack of significant petrographic differences between the analyzed samples, suggesting that the potters applied similar technical choices in the manufacture of both plain and decorated vessels. At the

i Consejo Nacional de Investigaciones Científicas y Técnicas / Instituto Nacional de Antropología y Pensamiento Latinoamericano, 3 de febrero 1387, Ciudad de Buenos Aires (C1426BJN), Argentina. Correo-e: flaviaott7@gmail.com. 
same time, some petrographic characteristics specific to "coarse ware" are detected, indicating the implementation of particular technological choices for the elaboration of these artifacts.

Keywords: Petrographic Analysis, Ceramic Art, Middle Paraná Basin, Late Holocene.

\section{INTRODUCCIÓN}

La alfarería constituye el elemento más asiduo del registro arqueológico de la cuenca del Paraná, Nordeste argentino (Figura I) y el soporte material conservado más importante de las expresiones artísticas de los grupos prehispánicos que habitaron la región. En los estudios sobre cerámica existió históricamente una tendencia a desvincular el análisis tecnológico del artístico, entre los cuales se verificó un escaso diálogo mutuo. Como ha sido señalado en detalle (Ottalagano 20l4), ambos ejes de estudio corrieron trayectorias muy diferentes en la región del Paraná. Mientras que los análisis tecnológicos mantuvieron un impulso continuo a lo largo de las investigaciones locales y contaron con una mayor pluralidad de acercamientos teórico-metodológicos, los estudios artísticos desarrollaron por el contrario una evolución discontinua, estuvieron teóricamente sesgados y carecieron prácticamente de aproximaciones metodológicas.

Junto con el desarrollo de las primeras excavaciones en la región, numerosos autores buscaron sistematizar y analizar el abundante material de alfarería recuperado (e.g. Aparicio 1923; Badano 1946; Lothrop 1932; Outes 1918; Serrano 1929, 1950, 1958; Torres 1903; Zeballos y Pico 1878). El interés por los aspectos técnicos de las vasijas se instaló inicialmente en la arqueología del Paraná con algunos trabajos pioneros, como el de Outes (1918), donde mediante aproximaciones experimentales, se buscó profundizar en el estudio de las pastas cerámicas como una vía para determinar contactos culturales entre grupos. Si bien el estudio de la tecnología cerámica se supeditó en un comienzo a nociones teóricas histórico-culturales, se introducen aquí herramientas metodológicas para abordar variables tecnológicas. No sucede lo mismo con las variables artísticas, las cuales fueron tratadas de manera descriptiva y predominantemente bajo conceptos difusionistas (e.g. Aparicio 1923; Badano 1946; Frenguelli 1927; Outes 1918; Serrano 1950, 1958). En pocos casos se intentaron abordajes alternativos basados en las premisas del totemismo
(Gaspary 1950; Torres 1911), los cuales carecieron de propuestas metodológicas que los respaldaran. Al abandonarse los planteos histórico-culturales, hacia la segunda mitad de siglo $\mathrm{XX}$, el estudio del arte quedó rezagado y perdió conexión con los estudios tecnológicos.

La necesidad de generar conocimiento sobre los gestos técnicos de los ceramistas dentro de un marco propiamente tecnológico, se consolida y se difunde a nivel mundial con obras como las de Shepard (1956), y especialmente a partir de la década de 1960 con el auge de la Nueva Arqueología. Esta necesidad, sin embargo se verifica más tardíamente en el panorama local. Las aproximaciones cualitativas con respecto a las variables tecno-formales empiezan a cobrar fuerza hacia las décadas de 1970 y 1980 (e.g. Caggiano 1979; Ceruti et al. 1980; Schmitz et al. 1972), pero no es sino acercándose al siglo XXI cuando se comienzan a realizar trabajos específicos sobre cerámica. A partir de entonces, el enfoque tecnológico se hizo patente en los estudios sobre alfarería, despojándose de sus legados históricoculturales previos y adquiriendo conceptos teóricometodológicos acordes a otras opciones teóricas, como la arqueología conductual (Letieri 1998) y la ecología evolutiva (Loponte 2008; Pérez 2010). La implementación de estos conceptos permitió incrementar el conocimiento referente a la producción, manufactura y función de la alfarería, así como contribuyó a entender la tecnología cerámica dentro de estrategias destinadas a incrementar la explotación del ambiente. En este punto ha sido crucial la incorporación de los análisis petrográficos, los cuales han llevado a acrecentar cualitativamente y cuantitativamente los datos cerámicos.

La petrografía es considerada actualmente una de las técnicas analíticas indispensables de los estudios cerámicos modernos, capaz de proveer datos esenciales en pos de resolver una amplitud de temáticas arqueológicas (Peterson 2009). La utilización explícita y a gran escala de la petrografía para el estudio de la alfarería no se concreta sino hasta los trabajos de Shepard, donde los análisis de 


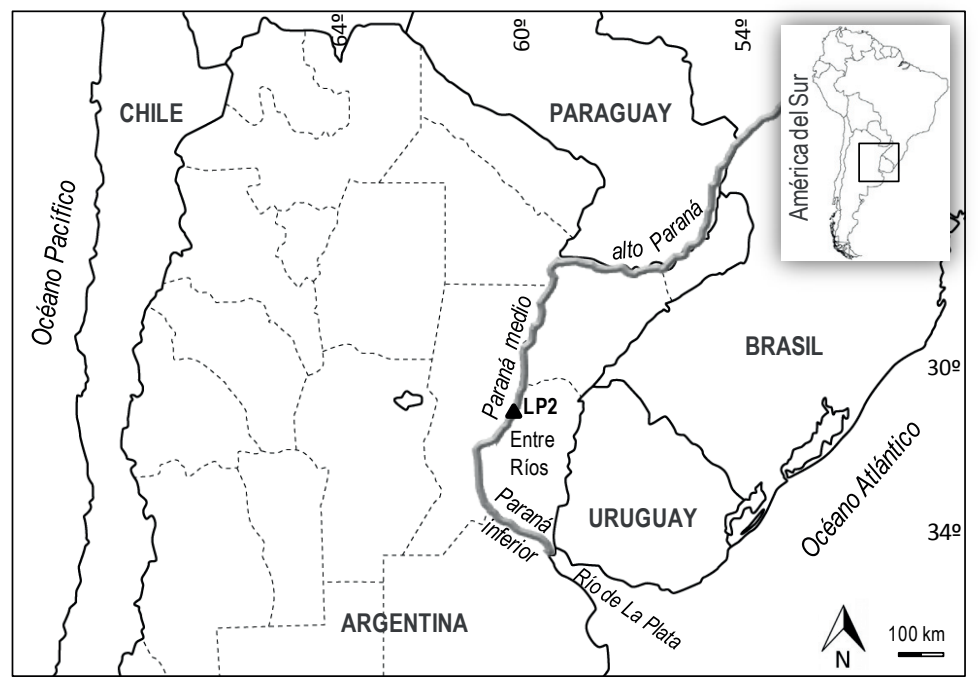

Figura 1: Localización geográfica del sitio La Palmera 2 en el Paraná medio.

Figure 1: Geographical location of La Palmera 2 site in the middle Paraná.

secciones delgadas de cerámica permiten a la autora distinguir diferentes tipos de vasijas (Shepard 1942, 1965; ver también Felts 1942). Si bien la petrografía cerámica comienza a aplicarse en otras regiones de Argentina desde fines de la década de 1980 (Balesta y Williams 2007), esta técnica arqueométrica cuenta con una baja y reciente presencia en la cuenca del Paraná. En lo que respecta a conjuntos cerámicos prehispánicos, los análisis petrográficos se han circunscripto a materiales del Paraná inferior (Capdepont Caffa y Bonomo 2012; Loponte 2008; Ottalagano y Pérez 2013; Ottalagano 2013; Pérez y Montenegro 2009; Pérez et al. 2009; Pérez 2010), no existiendo todavía datos petrográficos sobre alfarerías arqueológicas de otros sectores de la cuenca.

Este trabajo propone un nuevo acercamiento a las expresiones artísticas de los grupos prehispánicos del Paraná, por medio del estudio sistemático de sus características microscópicas (petrográficas). En este marco, se ofrece una propuesta de análisis que posibilita contextualizar esta información, comparando pautas tecnológicas entre recipientes decorados y no decorados. Una comparación tecno-morfológica entre diferentes categorías de artefactos fue realizada previamente a nivel macroscópico para la cerámica del Paraná medio (Ottalagano 2009), otorgando algunas expectativas que esperan ser discutidas y contrastadas con los datos petrográficos obtenidos. Se analizan, en particular, secciones delgadas de tiestos cerámicos recuperados en La Palmera 2: un sitio de actividades múltiples (Ceruti 2003), asociado a ocupaciones fundamentalmente cazadoras-recolectoras y que cuenta con dos dataciones radiocarbónicas de 1056 \pm 47 años AP y 1032 \$47 años AP (Ottalagano et al. 20I3) (Figura I). Este análisis representa un caso de estudio, que puede ser posteriormente aplicado a otros sitios del área, y que busca conciliar la brecha que tradicionalmente ha disociado los estudios tecnológicos de los artísticos en la cuenca del Paraná.

\section{CARACTERÍSTICAS MACROSCÓPICAS DEL REGISTRO CERÁMICO LOCAL: PRINCIPALES TENDENCIAS ENTRE CATEGORÍAS ARTEFACTUALES}

El arte prehispánico de la cuenca del río Paraná está constituido principalmente por recipientes de alfarería con decoración incisa, monocroma y modelada figurativa. Entre éstas últimas resultan distintivas las figuras de aves, las cuales han sido representadas en la cerámica de manera recurrente por las poblaciones que habitaron extensos sectores costeros de los ríos Paraná y Uruguay, y parte del Rio de La Plata (Ceruti 2003) (Figura 2). 
Sobre la base de los estudios efectuados sobre conjuntos cerámicos de 9 sitios arqueológicos de la margen entrerriana del Paraná medio, entre los que se incluye el sitio La Palmera 2, se ha puesto en evidencia ciertas semejanzas y divergencias tecnomorfológicas y de uso entre categorías artefactuales (Ottalagano 2009). Dichas categorías comprendieron: a) recipientes lisos, b) recipientes con presencia exclusiva de pintura roja (total o zonal: anchas franjas paralelas al borde), y c) recipientes con motivos abstractos y figurativos (incisos y/o modelados), algunas veces con el agregado de pintura roja o blanca. Entre estos últimos se consideraron asimismo las denominadas "campanas", las cuales suelen estar decoradas igualmente por guardas incisas $y / 0$ motivos zoomorfos, y en algunos casos también por pintura blanca. Las "campanas" o "alfarerías gruesas" son piezas peculiares que se registran asiduamente en un amplio sector del río Paraná y áreas asociadas (Ceruti 2003; Gaspary 1950; Lothrop 1932; Serrano 1958, entre otros). Se caracterizan por presentar una forma ligeramente acampanada con dos aberturas: una superior y otra basal, que las convierte en vasijas sin fondo y que las inutiliza como contenedores' (Figura 2).

De acuerdo a los estudios realizados ${ }^{2}$, los recipientes decorados con guardas incisas y motivos figurativos, tienden a presentar amplias semejanzas morfológicas con las vasijas lisas. En ambos casos se registran recipientes de variados tamaños, tipológicamente asignables a escudillas, cuencos y ollas (sensu Balfet et al. 1983). La existencia de vasijas restringidas y abiertas en ambas categorías artefactuales, supone la necesidad de cubrir una amplia gama de actividades, relacionadas tanto con el almacenamiento como con la manipulación, despliegue o secado de los elementos contenidos (Shepard 1956). Es de destacar, que los rastros de utilización (restos carbonosos, lípidos) que son altamente frecuentes en los recipientes lisos del área, se han registrado asimismo en vasijas con este tipo de decoraciones, sugiriendo que tanto las vasijas lisas como las decoradas fueron empleadas para la cocción y procesamiento de los alimentos.

Los recipientes pintados, por el contrario, tienden a exhibir ciertas particularidades visibles macroscópicamente que los diferencian de los recipientes lisos. Éstos registran formas casi exclusivamente abiertas, muchas de ellas tipo plato (sensu Balfet et al. 1983). La pintura presenta una marcada localización interna y generalmente está muy bien conservada. Suele ser baja la presencia de vasijas pequeñas, con aberturas inferiores a los $15 \mathrm{~cm}$, frecuentes entre los recipientes lisos, por ejemplo. Tienden a presentar superficies muy bien alisadas, con una regularidad superficial algo mayor que la exhibida por las otras categorías artefactuales, y con mayor presencia de engobe. En esta categoría artefactual no hay registros de bordes con espesores muy gruesos $(>0,9 \mathrm{~cm})$, que puedan ser adjudicados a campanas. Tampoco se observan en sus superficies restos carbonosos ni adherencias que puedan ser resultado de la cocción de alimentos.

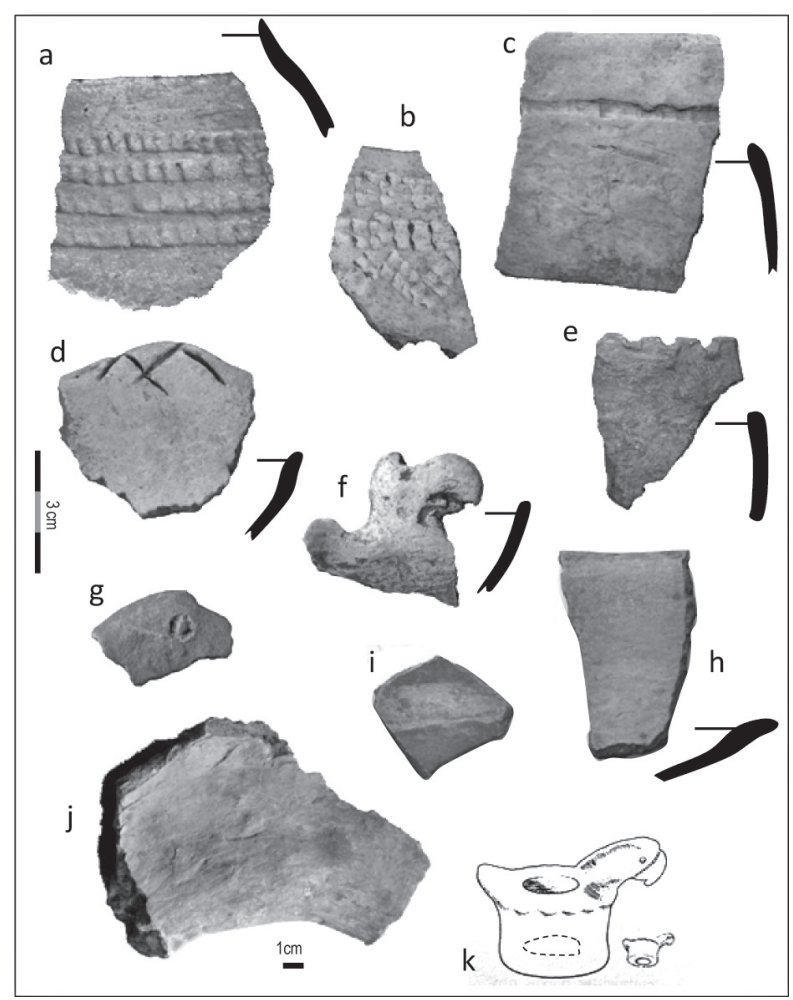

Figura 2: Ejemplos de tiestos seleccionados para cortes delgados: a)-e) tiestos con decoración incisa; f)-g) tiestos con decoración zoomorfa; h)-i) tiestos decorados con pintura roja: total y zonal; j) borde basal de "alfarería gruesa"; k) reconstrucción de "campanas" zoomorfas (tomado y modificado de Serrano 1946).

Figure 2: Examples of selected sherds for thin sections: a)-e) sherds with incised decoration; $f$ ) $-g$ ) sherds with zoomorphic decoration; h)-i) sherds decorated with red paint: total and zonal; $j$ ) basal edge of "alfarería gruesa"; $k$ ) reconstruction of zoomorphic "campanas" (taken and modified from Serrano 1946). 
Más allá de estas diferencias, tanto los recipientes lisos como los decorados con pintura, incisión y modelado figurativo, manifiestan no obstante ciertas similitudes tecno-morfológicas de base. En todos los casos son usuales las formas de contornos simples con cuellos invertidos, algunas de ellas con orificios de suspensión. Se registra una buena proporción de fracturas finas y pastas con núcleos y márgenes generalmente oscuros, debido probablemente a una atmósfera restringida en oxígeno (Convención Nacional de Antropología 1966). La ausencia casi total de texturas flojas y la presencia minoritaria de fracturas muy ásperas - cortantes, sugiere que los recipientes fueron quemados a temperaturas por encima de los $600^{\circ}$ C (Rice 1987). Las alfarerías gruesas, por su parte, se distinguen no sólo por su forma acampanada de anchas paredes, sino también por presentar otros atributos macroscópicamente observables, tales como el color de su pasta. Se registran tonalidades naranjas y rojizas, propias de la oxidación de los componentes de la pasta (Ottalagano 2009). Esto podría reflejar requerimientos técnicos específicos, necesarios para confeccionar alfarerías con segmentos de pasta muy gruesos, donde se hace preciso prologar la quema o exponer los artefactos a temperaturas más elevadas (Orton et al. 1997; Shepard 1956).

En base a estos datos, se propuso considerar las similitudes tecno-morfológicas observables entre recipientes lisos y decorados (con motivos abstractos y figurativos realizados mediante incisión y modelado) como un posible indicador de desempeños comunes (sensu Schiffer y Skibo 1987), mayormente asociados a tareas de carácter doméstico, dada la presencia de rastros de utilización en ambas categorías. Ciertos aspectos de la manufactura de los recipientes pintados y de las alfarerías gruesas, por el contrario, se habrían desarrollado de acuerdo a conductas tecnológicas particulares, haciendo pensar en categorías artefactuales distintas y probablemente vinculadas cada una a un uso diferencial (Ottalagano 2009).

\section{CRITERIOS TEÓRICOS-METODOLÓGICOS}

La finalidad de este trabajo es obtener información sobre los comportamientos tecnológicos implicados en las vasijas decoradas, observando en cuánto difieren o se asemejan a las conductas tecnológicas encontradas en los recipientes lisos: el prototipo de los artefactos domésticos. Se parte de la base que las vasijas cerámicas forman parte del contexto del arte. Por consiguiente, profundizar en los aspectos tecnológicos de éstas se vuelve un modo complementario de acceder a cierta información acerca de las potenciales funciones desarrolladas por los recipientes decorados.

Dejando de lado los factores relacionados con la disponibilidad de materias primas, las elecciones técnicas que aplican los alfareros a lo largo del proceso de manufactura de una vasija pueden verse influenciadas por dos grandes grupos de variables: la función del recipiente y las preferencias y significados socialmente establecidos. A diferencia del uso, que es la forma concreta en que es utilizada una vasija en una situación dada, la función hace referencia a las capacidades generales de los artefactos cerámicos para desempeñarse de forma óptima en determinadas tareas, como almacenamiento, procesamiento y transporte (Rice 1996).

Todas las actividades que constituyen las distintas etapas del proceso de manufactura de los artefactos cerámicos están conformadas por una secuencia de comportamientos que son el resultado de elecciones técnicas específicas, las cuales dependen en gran medida de los conocimientos y la experiencia del artesano. Cada elección técnica tiene un efecto concreto sobre las propiedades de las vasijas, como por ejemplo, sobre la porosidad, la resistencia del material cerámico al estrés térmico y la eficacia calorífica. Estos atributos artefactuales, a su vez, pueden influenciar la clase tareas que una pieza cerámica puede llegar a desempeñar. Por lo tanto, una buena parte de la variabilidad artefactual es producto, entonces, de la conducta del artesano en pos de optimizar las vasijas para afrontar actividades específicas (Skibo 2013; Schiffer y Skibo 1987, 1997).

Una elección técnica implica una toma de decisión implícita o explícita y supone la existencia de un repertorio de operaciones alternativas igualmente posibles, pero no seleccionadas (Schiffer y Skibo 1997). Algunos autores han señalado que en estas decisiones tecnológicas intervienen también comportamientos estilísticos (e.g. Lechtman 1977; Lemonnier 1992). Frente a este abanico de opciones alternativas de modos de hacer artefactos, los artesanos seleccionan sólo algunas sobre la base, por 


\begin{tabular}{|c|c|c|c|c|c|}
\hline \multicolumn{2}{|c|}{ Muestra } & \multirow{2}{*}{$\begin{array}{c}\text { Decoración } \\
\text { No }\end{array}$} & \multirow{2}{*}{$\begin{array}{c}\begin{array}{c}\text { Forma } \\
\text { recipiente }\end{array} \\
\text { abierta } \\
\end{array}$} & \multirow{2}{*}{$\begin{array}{c}\begin{array}{c}\text { Grosor } \\
\text { pared }(\mathbf{c m})\end{array} \\
0,7 \\
\end{array}$} & \multirow{2}{*}{$\begin{array}{r}\begin{array}{r}\text { Diámetro } \\
\text { boca (cm) }\end{array} \\
34 \text { a } 42\end{array}$} \\
\hline I & borde & & & & \\
\hline 2 & borde & No & abierta & 0,5 & 32 a 46 \\
\hline 3 & borde & No & cerrada & 0,6 & 14 \\
\hline 4 & borde & No & cerrada & 0,8 & 32 a 46 \\
\hline 5 & borde & No & abierta & 0,8 & 22 a 30 \\
\hline 6 & borde & No & indet. & 0,7 & 25 a 36 \\
\hline 7 & borde & No & abierta & 0,5 & 32 a 38 \\
\hline 8 & borde & No & cerrada & 0,5 & 25 \\
\hline 9 & borde & No & abierta & 0,5 & $>40$ \\
\hline 10 & borde & No & cerrada & 0,8 & 27 a 40 \\
\hline II & borde & No & cerrada & 0,8 & 21 \\
\hline 12 & borde & No & abierta & 0,6 & $>40$ \\
\hline 13 & borde & No & cerrada & 0,7 & 22 a 24 \\
\hline 14 & borde & No & indet. & 0,9 & $>50$ \\
\hline 15 & cuerpo & pintura blanca & campana & 2,5 & indet. \\
\hline 16 & borde & No & campana & 2,1 & indet. \\
\hline 17 & borde & pintura blanca & campana & 1,5 & indet. \\
\hline 18 & borde & modelado zoomorfo & abierta & 0,5 & 18 a 20 \\
\hline 19 & borde & incisión de surco rítmico & cerrada & 0,8 & 16 \\
\hline 20 & borde & incisión de surco rítmico & indet. & 0,9 & 34 \\
\hline 21 & borde & incisión de surco rítmico & cerrada & 0,4 & 16 \\
\hline 22 & borde & $\begin{array}{l}\text { modelado zoomorfo y surco } \\
\text { rítmico }\end{array}$ & abierta & 0,7 & 22 \\
\hline 23 & borde & incisión de surco rítmico & abierta & 0,5 & 28 \\
\hline 24 & cuerpo & incisión: de punto y surco rítmico & indet. & 0,5 & indet. \\
\hline 25 & cuerpo & incisión de línea & indet. & 0,7 & indet. \\
\hline 26 & borde & incisión de línea & abierta & 0,6 & 13 \\
\hline 27 & borde & incisión de línea & abierta & 0,7 & 14 \\
\hline 28 & borde & incisión: punto y s. rítmico + p. roja & abierta & 0,5 & 26 \\
\hline 29 & borde & pintura roja & abierta & 0,7 & 32 a 36 \\
\hline 30 & borde & pintura roja & abierta & 0,9 & 32 a 48 \\
\hline 31 & borde & pintura roja & abierta & 0,9 & 32 a 36 \\
\hline 32 & borde & pintura roja & abierta & 0,85 & $>40$ \\
\hline 33 & borde & pintura roja & abierta & 0,7 & $>50$ \\
\hline 34 & borde & pintura roja & abierta & 0,7 & 44 \\
\hline 35 & borde & pintura roja & indet. & 0,6 & $>42$ \\
\hline 36 & borde & pintura roja & abierta & 0,6 & 28 \\
\hline 37 & cuerpo & pintura roja & indet. & 0,4 & indet. \\
\hline
\end{tabular}

Tabla 1: Características macroscópicas de las muestras cerámicas seleccionadas.

Table 1: Macroscopic features of selected ceramic samples. 
ejemplo, de tradiciones artesanales. Sackett (1985) denominó estilo isocréstico a aquellas elecciones específicas que toman los alfareros entre varias opciones disponibles y equivalentes en función. Así, algunas elecciones técnicas relacionadas con la selección de las materias primas o el modo en que son elaboradas las piezas cerámicas puede encontrarse influenciadas por prescripciones sociales e incluso también simbólicas, como plantean Gosselain y Livingstone-Smith (2005), entre otros autores.

\section{Muestra de Estudio}

Se examinaron 37 secciones delgadas de cerámica correspondientes a vasijas de distintas formas y tamaños, recuperadas durante las nuevas excavaciones realizadas en La Palmera 2 (Ottalagano et al. 2013). Los tiestos elegidos como muestras de estudio pertenecen a recipientes que son altamente representativos del registro cerámico regional, y se corresponden con los siguientes grupos artefactuales: a) recipientes lisos, b) campanas o alfarerías gruesas, con o sin pintura blanca, c) recipientes con motivos zoomorfos y/o decoración incisa y d) recipientes exclusivamente decorados con pintura roja, total - zonal (anchas franjas paralelas al borde) (Tabla I, Figura 2). Una sola muestra presentó a la vez decoración incisa y pintura roja, la cual fue incluida dentro del tercer grupo.

Las muestras se recuperaron en los sectores y niveles del sitio con mayor potencia arqueológica: entre los 0,20-0,60 m de profundidad y en contextos domésticos. Se seleccionaron casi exclusivamente bordes, por los siguientes motivos: a) para poder identificar claramente los recipientes lisos de los decorados, ya que en el registro cerámico regional la decoración incisa y modelada se presenta casi exclusivamente en el sector próximo al borde de las vasijas; b) por ser elementos diagnósticos de las formas y dimensiones de las alfarerías; c) porque son fáciles de orientar en función del tipo de corte petrográfico elegido; $y$ d) a fin de evitar ingresar al análisis más de un tiesto de una misma vasija. Los tiestos no presentaron rastros macroscópicos de utilización (adherencias, hollín), salvo en dos muestras de alfarerías gruesas, en las que se detectó muy escasas adherencias internas. Por tratarse prácticamente de bordes, cabe la posibilidad sin embargo que existieran rastros de uso en porciones de cuerpo de las vasijas.

Las secciones delgadas de cerámica se analizaron utilizando un microscopio petrográfico con luz polarizada plana y cruzada, con un rango de aumentos de entre 40 x y 400 x. Cada tipo de corte petrográfico (tangencial, vertical, horizontal) restringe o facilita determinada información (Rye 1981; Whitbread 1996; Woods 1985). En este caso se optó por la realización de cortes horizontales $(n=25)$ y verticales $(n=I I)$ (sensu Woods 1985), ya que se adaptan mejor al tipo de muestra seleccionada, además que permiten obtener datos complementarios con respecto a la orientación de poros e inclusiones. La muestra $n^{\circ} 37$ es la única cuyo corte no pudo ser orientado, por tratarse de un fragmento de cuerpo de muy pequeño tamaño. Se registraron atributos en relación a: I) la matriz (relación porcentual de los componentes de la pasta, textura), 2) las inclusiones (tipo, frecuencia, ordenamiento,forma y tamaño),y3) porosyoquedades (orientación, tamaño, forma y abundancia). Se utilizó la escala granulométrica de Udden-Wentworth (en Adams et al. 1984) para categorizar el tamaño de los antiplásticos y los gráficos de Barraclough (1992) para determinar el grado de esfericidad-angulosidad de los mismos, así como su escala de ordenación. Se emplearon las cartas visuales de Mathew et al. (1991) y aquellas expresadas por PCRG (2010) para calcular la frecuencia de los distintos componentes identificados en las pastas.

\section{ANÁLISIS PETROGRÁFICO DE LA CERÁMICA}

\section{Matriz y relación porcentual entre componen- tes de la pasta}

El estudio petrográfico determinó la presencia de pastas cerámicas caracterizadas por un alto porcentaje de matriz en relación al contenido de inclusiones, poros y oquedades (Tabla 2). Las matrices representan más de la mitad de los componentes de las pastas cerámicas. Las mismas se observan como agregados granulares de textura muy fina (sensu Aguilar et al. 1998). No se observan signos de vitrificación, lo cual indica que la quema de las alfarerías no alcanzó temperaturas muy elevadas, ya 


\begin{tabular}{|c|c|c|c|c|c|c|c|c|c|}
\hline \multirow{2}{*}{\multicolumn{2}{|c|}{$\begin{array}{c}\text { Vasija/ } \\
\text { Muestra }\end{array}$}} & \multicolumn{3}{|c|}{$\begin{array}{l}\text { Relación porcentual entre } \\
\text { componentes de la pasta }\end{array}$} & \multicolumn{5}{|c|}{$\begin{array}{l}\begin{array}{l}\text { Porcentaje relativo de los principales grupos de } \\
\text { inclusiones }\end{array} \\
\end{array}$} \\
\hline & & \multirow{2}{*}{$\begin{array}{c}\text { Matriz } \\
59 \\
\end{array}$} & \multirow{2}{*}{$\begin{array}{c}\begin{array}{c}\text { Inclu- } \\
\text { siones }\end{array} \\
40\end{array}$} & \multirow{2}{*}{$\begin{array}{c}\begin{array}{c}\text { Poros/ } \\
\text { oquedades }\end{array} \\
\text { I }\end{array}$} & \multirow{2}{*}{$\begin{array}{c}\text { Minerales } \\
65\end{array}$} & \multirow{2}{*}{\begin{tabular}{|c|}
$\begin{array}{c}\text { Nódulos } \\
\text { (óxidos) }\end{array}$ \\
30 \\
\end{tabular}} & \multirow{2}{*}{$\begin{array}{c}\begin{array}{c}\text { Tiesto } \\
\text { molido }\end{array} \\
-\end{array}$} & \multirow{2}{*}{$\begin{array}{c}\begin{array}{c}\text { Restos } \\
\text { carbonosos }\end{array} \\
\mathrm{I} \\
\end{array}$} & \multirow{2}{*}{$\begin{array}{c}\text { Otro } \\
4 \\
\end{array}$} \\
\hline \multirow{14}{*}{ 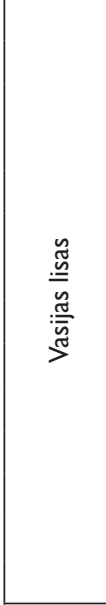 } & I & & & & & & & & \\
\hline & 2 & 68 & 25 & 7 & 49 & 46 & I & 2 & 2 \\
\hline & 3 & 65 & 25 & 10 & 40 & 49 & 7 & I & 3 \\
\hline & 4 & 59 & 40 & $\mathrm{I}$ & 59 & 39 & $\mathrm{I}$ & - & I \\
\hline & 5 & 73 & 20 & 7 & 12 & 70 & 15 & I & 2 \\
\hline & 6 & 57 & 40 & 3 & 47 & 32 & 20 & - & I \\
\hline & 7 & 84 & 15 & I & 48 & 47 & 3 & - & 2 \\
\hline & 8 & 72 & 25 & 3 & 62 & 30 & 5 & - & 3 \\
\hline & 9 & 55 & 20 & 25 & 50 & 47 & - & 2 & I \\
\hline & 10 & 60 & 30 & 10 & 52 & 47 & - & - & 1 \\
\hline & 11 & 50 & 30 & 20 & 30 & 55 & 12 & I & 2 \\
\hline & 12 & 65 & 25 & 10 & 40 & 43 & 10 & - & 7 \\
\hline & 13 & 78 & 15 & 7 & 30 & 65 & - & - & 5 \\
\hline & 14 & 80 & 15 & 5 & 43 & 45 & 7 & 2 & 3 \\
\hline \multicolumn{2}{|c|}{ Promedio } & $66(\mathrm{~s} 10,1)$ & 26 (s 9) & 8 (s 7) & 44,8 (s I4) & $46(\mathrm{~s} I I, 7)$ & 5,8 (s 6,4) & 0,8 (s 0,8) & 2,6 \\
\hline \multirow{3}{*}{ 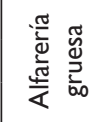 } & 15 & 83 & 10 & $7 *$ & 40 & 49 & 5 & $\mathrm{I}$ & 5 \\
\hline & 16 & 83 & 7 & $10 *$ & 33 & 55 & 7 & - & 5 \\
\hline & 17 & 80 & 10 & 10 & 31 & 55 & 12 & - & 2 \\
\hline \multicolumn{2}{|c|}{ Promedio } & $82(\mathrm{~s} I, 7)$ & $9(\mathrm{~s} \mathrm{I}, 7)$ & $9(\mathrm{~s} \mathrm{I}, 7)$ & 34,6 (s 4,7) & $53(s$ 3,4) & $8(s$ 3,6) & 0,4 (s 0,5) & 4 \\
\hline \multirow{11}{*}{ 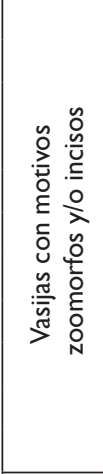 } & 18 & 70 & 25 & 5 & 43 & $4 I$ & 15 & - & 1 \\
\hline & 19 & 50 & 40 & 10 & 61 & 35 & 2 & $\mathrm{I}$ & I \\
\hline & 20 & 65 & 20 & 15 & 33 & 40 & 20 & 2 & 5 \\
\hline & 21 & 70 & 20 & 10 & 51 & 40 & 3 & $\mathrm{I}$ & 5 \\
\hline & 22 & 60 & 25 & 15 & 45 & 52 & - & I & 2 \\
\hline & 23 & 60 & 30 & 10 & 54 & 40 & 5 & - & 1 \\
\hline & 24 & 75 & 15 & 10 & $4 I$ & 51 & 1 & 2 & 5 \\
\hline & 25 & 60 & 20 & 20 & 25 & 68 & $\mathrm{I}$ & 2 & 4 \\
\hline & 26 & 65 & 20 & 15 & 12 & 64 & 20 & I & 3 \\
\hline & 27 & 60 & 25 & 15 & 60 & 29 & 1 & 5 & 5 \\
\hline & 28 & 53 & 40 & 7 & 52 & 15 & 30 & $\mathrm{I}$ & 2 \\
\hline \multicolumn{2}{|c|}{ Promedio } & 62,5 (s 7,4) & 25,5 (s 8,2) & $12(s 4,3)$ & 43,5 (s I5) & 43,1 (s I5, I) & 8,9 (s 10,4) & $\mathrm{I}, 5(\mathrm{~s} \mathrm{I}, 3)$ & 3 \\
\hline \multirow{9}{*}{ 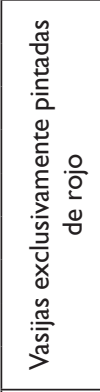 } & 29 & 70 & 20 & $10 *$ & 54 & 30 & 15 & - & 1 \\
\hline & 30 & 60 & 20 & 20 & 37 & 43 & 15 & 2 & 3 \\
\hline & 31 & 60 & 30 & 10 & 22 & 70 & 5 & I & 2 \\
\hline & 32 & 60 & 25 & $15 *$ & 15 & 81 & 3 & - & I \\
\hline & 33 & 65 & 30 & 5 & 60 & 39 & - & - & 1 \\
\hline & 34 & 77 & 20 & 3 & 46 & 45 & 7 & - & 2 \\
\hline & 35 & 60 & 25 & 15 & 27 & 57 & 12 & I & 3 \\
\hline & 36 & 82 & 15 & 3 & 27 & 70 & 2 & - & 1 \\
\hline & 37 & 59 & 40 & $\mathrm{I}$ & 78 & 21 & - & - & 1 \\
\hline \multicolumn{2}{|c|}{ Promedio } & 66 (s 8,5) & $25(s 7,5)$ & $9(s, 6,5)$ & 40,7 (s 20,5) & 50,6 (s 20, I) & 6,5 (s 6) & 0,5 (s 0,7) & $\mathrm{I}, 7$ \\
\hline
\end{tabular}

Nota: $s=$ Desvío estándar; $\left(^{*}\right)$ Se detecta una elevada proporción de oquedades: igual o mayor a la de poros.

Tabla 2:Atributos petrográficos de las muestras cerámicas.

Table 2: Petrographic features of ceramic samples. 
que este proceso por lo general ocurre por encima de los $900^{\circ}$. Esto es coherente con una cochura de las piezas cerámicas a cielo abierto, donde las temperaturas raramente exceden este rango. No obstante, por encima de los $800^{\circ}-850^{\circ}$ tiene lugar una incipiente vitrificación en la cual las partículas de la matriz comienzan a ablandarse y fusionarse (Gibson y Wood 1997; Rye 1981; Shepard 1956). Esta característica no ha podido ser reconocida en las muestras cerámicas analizadas, lo que hace suponer que las temperaturas se mantuvieron por debajo de este límite.

La estructura de las pastas -es decir, la relación porcentual que mantienen sus diferentes componentes entre sí- presenta variabilidad en las muestras. Las pastas analizadas pueden ser agrupadas en al menos tres categorías en base a su estructura: a) pastas con alta proporción de antiplásticos y baja porosidad: muestras I, 2, 4, 6, 8, I8, 28, 33, 34, 37; b) pastas con elevada frecuencia tanto de inclusiones como de poros: muestras 9, II, 25, 30; y c) pastas con moderada a baja proporción de poros y de inclusiones: muestras 13, 14, 15, 16, 17, 24, 36. Las restantes muestras exhiben diversos gradientes de porosidad y de material antiplástico (Tabla 2), ubicándose en puntos intermedios de los grupos de pasta mencionados.

Si se compara la estructura de la pasta de recipientes lisos y decorados, no se observan diferencias significativas. Sólo la categoría artefactual representada por las alfarerías gruesas mantiene una correspondencia con un grupo de pasta específico: el grupo C. Por lo general, los índices de porosidad son inferiores a la proporción de inclusiones, cuya frecuencia suele ser igual o superior al $15 \%$. Los cortes delgados de las alfarerías gruesas, no obstante, son los únicos que manifiestan densidad de antiplásticos inferiores a ese porcentaje (Tabla 2).

\section{Poros y oquedades}

Las diferencias estructurales encontradas en las pastas pueden ser resultado de la variabilidad natural de las arcillas utilizadas, pero también pueden deberse a las distintas elecciones técnicas implementadas por los alfareros. Así por ejemplo, la frecuencia y forma de los poros y oquedades está relacionada con la intensidad del amasado y con las técnicas de manufactura empleadas, entre otros factores (Livingstone-Smith 2007; Peterson 2009; Pierret 1996; Rye 198I). Más de la mitad de las muestras presenta una considerable densidad de poros, en proporciones mayormente moderadas ( 10 I5\%) y en algunos casos frecuente (20-25\%) (Figura $3)$. En algunas de ellas, por el contrario, se observa porosidad muy baja ( I-3 \%) (Tabla 2).

Cabe destacar que estos valores se refieren principalmente a la frecuencia de poros, ya que las oquedades son más bien escasas en las muestras. Las mismas se detectan en abundancia en algunas muestras, y en especial en el grupo de las alfarerías gruesas (Tabla 2). Su tamaño suele variar entre los 0,5-2 $\mathrm{mm}$. Las oquedades son consecuencia generalmente de un trabajo de amasado inadecuado y se distinguen por su aspecto irregular, de tamaño bastante mayor al de los poros. La porosidad, por el contario, se origina cuando hay un apropiado amasado de las materias primas y representa un rasgo positivo que tiende a incrementar la resistencia de las vasijas al estrés térmico, al evitar que se expandan posibles grietas producidas por las contracciones sufridas por el material al exponerse al calor (Arnold 1985; Rye 1981; Shepard 1956).

Los poros registran formas elongadas, orientados longitudinalmente a la pared de las vasijas en los cortes horizontales y de forma preferentemente aleatoria en cortes verticales (Figura 3 y 4). Como se ha señalado (Livingstone-Smith 2007; Pierret 1996; Rye 1981; Woods 1985), la orientación de los componentes de la pasta es un atributo que guarda relación con el modo en que se ejerce presión sobre la arcilla, y por ende con las técnicas de manufactura de la cerámica. Cuando las secciones delgadas se cortan horizontalmente en vasijas manufacturadas mediante superposición de rodetes de arcilla, la orientación de los poros e inclusiones finas tiende a seguir un patrón paralelo o sub-paralelo a las superficies (paralelo a la dirección del rollo), también denominado fluidal (ver González de Bonaveri et al. 2000; Solá 2004). Por el contrario, cuando se trata de secciones verticales, la orientación de los componentes de la pasta asume un patrón azaroso en vasijas elaboradas por rollos, como consecuencia del efecto del corte realizado de manera perpendicular al rodete. La disposición paralela de los poros (en secciones horizontales) $(n=2 I)$ y aleatoria (en secciones verticales) $(n=6)$, es petrográficamente observable en las muestras correspondientes a los 


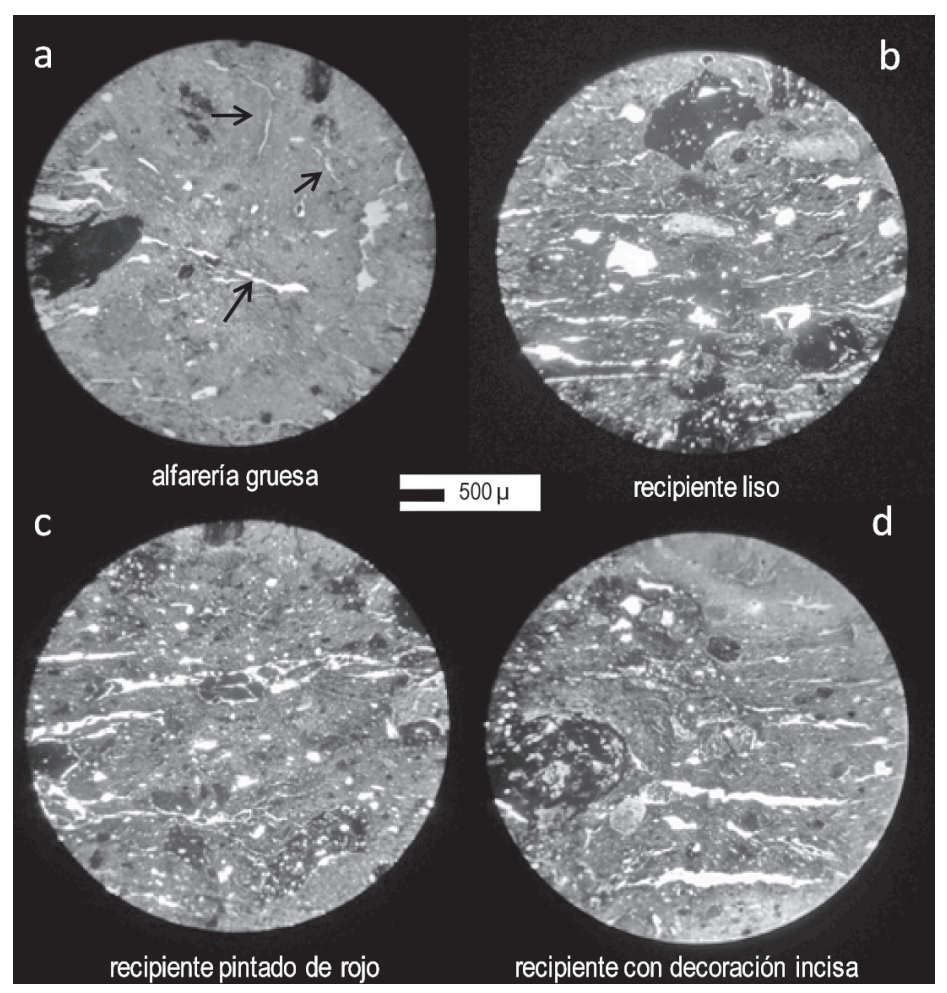

Figura 3: Orientación y frecuencia de poros en distintos artefactos (microfotografías de cortes delgados de cerámica bajo nicoles paralelos): a) poros con distintas orientaciones; porosidad escasa; b) c) y d) orientación paralela de poros; b) porosidad frecuente; c)-d) porosidad moderada.

Figure 3: Orientation and frequency of pores on different artifacts (microphotographs of ceramic thin sections under parallel nicols): a) pores with different orientations; low porosity; $b$ ), c) and d) parallel orientation of the pores; $b$ ) common frequency of pores; $c$ )-d) moderate porosity.

distintos grupos artefactuales (Figura 3 y 4), lo cual podría estar indicando que la técnica de manufactura primaria básica para casi todas las categorías de recipientes fue la de rodetes o coiling, la que ha sido ampliamente registrada de forma macroscópica en la arqueología regional (Serrano 1958). En una proporción menor de muestras $(n=3)$, se detectó orientación sub-paralela en secciones delgadas verticales (Figura 4), la cual puede estar vinculada con acciones de estiramiento de la pasta arcillosa en dirección vertical (Rye 198I; Livingstone-Smith 2007). En algunas muestras $(n=3)$, no fue posible identificar ningún patrón fluidal ni azaroso, posiblemente debido al bajo porcentaje de poros (Figura 4).

Una situación algo diferente se ofrece en las alfarerías gruesas donde se verifican poros con direcciones variables en cortes horizontales (Figuras
3 y 4). Esta característica puede estar indicando presiones discontinuas sobre la masa de arcilla, como ocurre por ejemplo en las técnicas de modelado o modeling (Livingstone-Smith 2007: Shepard 1956), tal como ha sido discutido para las alfarerías gruesas procedentes del Paraná inferior donde se observa un patrón similar (Loponte 2008; Ottalagano y Pérez 2013; Pérez 2010). Estas diferencias, no obstante, deberán precisarse en base a una mayor cantidad de muestras y varios parámetros de estudio. Debe tenerse en cuenta que el análisis petrográfico como vía de aproximación respecto de los modos en que se manufacturó la cerámica no es unívoco, por lo tanto requiere del aporte de otras técnicas analíticas como las radiográficas, a fin de precisar detalles en relación a la estructura interna de los recipientes (Carr 1993; Livingstone-Smith 2007; Rye 1981). 


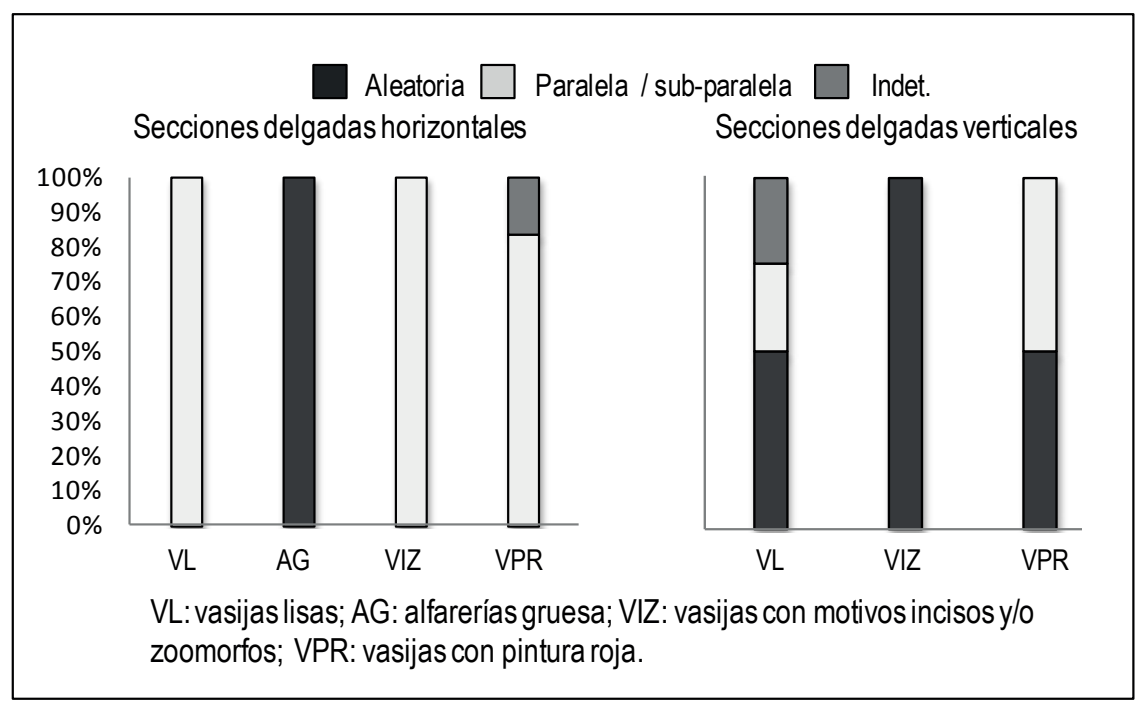

Figura 4: Orientación de poros e inclusiones.

Figure 4: Orientation of pores and inclusions.

Se observan, por último, otra clase de poros: aquellos que rodean las inclusiones, especialmente las de mayor tamaño. Los mismos son típicos de las contracciones que experimenta la matriz cuando el agua alojada entre sus partículas es eliminada durante los procesos de secado y cochura de las alfarerías. Este tipo de poros tienden a hacerse más visibles cuando la granulometría de la matriz es fina, como en los casos analizados (Gibson y Woods 1997). En algunas muestras se registran, además, ciertas grietas que corren perpendicularmente a la superficie de los tiestos (e.g. muestras II, I2, 13, 24, 29), las cuales pueden deberse a pequeñas fracturas ocasionadas igualmente durante las contracciones que experimenta la arcilla. Las mismas son usuales especialmente cuando la alfarería se ve expuesta a un rápido enfriamiento, lo cual es coherente con la quema abierta, donde las temperaturas ascienden y descienden de manera abrupta (Gibson y Woods 1997; Orton et al. 1997).

\section{Inclusiones}

Las muestras exhiben una elevada proporción de inclusiones minerales y nódulos compuestos por óxidos (Tabla 2, Figura 5). Entre estos últimos resulta muy abundante la hematita, de color rojo y a veces negro (Aguilar et al. 1998), que se presenta usualmente como grumos amorfos o esféricos de fracción muy gruesa ( $>I \mathrm{~mm}$ ), aunque también se los encuentra como granos más pequeños. En mucha menor proporción, se distinguen asimismo granos de magnetita, caracterizados por su aspecto negro opaco y con tamaños que por lo general se ubican dentro de la fracción fina $(<0,25 \mathrm{~mm})$.

Entre las inclusiones minerales se observan principalmente granos félsicos, los cuales se registran en gran proporción en todas las muestras. Los mismos corresponden mayoritariamente a cuarzos y en menor medida a feldespatos, incluyendo plagioclasas (Figura 5). Algunos feldespatos potásicos, aunque similares al cuarzo, se reconocen por su aspecto grisáceo sucio cuando se observan bajo nicoles cruzados (Aguilar et al. 1998). Particularmente la morfología y desgaste de los granos de cuarzo es utilizada para la determinación de su origen petrológico. En las muestras analizadas se registran tanto formas redondeadas como granos angulosos y con baja esfericidad, propios respectivamente de un origen sedimentario y volcánico (Aguilar et al. 1998; Orton et al. 1997). Sin embargo, en casi todas las muestras suelen predominar los cuarzos con morfologías generalmente angulosas o subangulosas. Se detectan también algunos minerales que presentan pleocroísmo, es decir que observan cambios en su coloración o en la intensidad de su color bajo los efectos de la luz polarizada, cuando se gira la platina del microscopio. De acuerdo a sus 


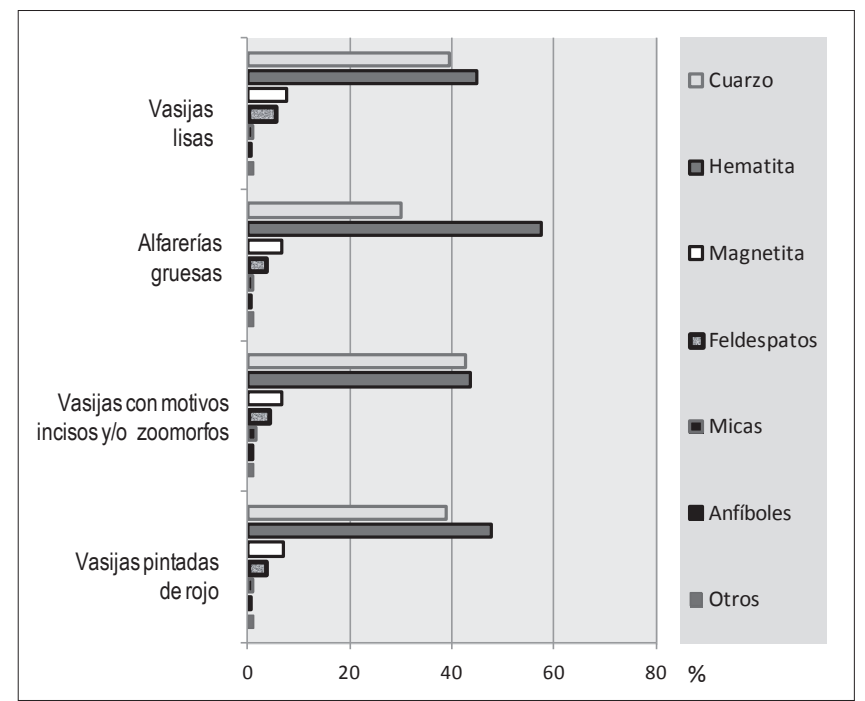

Figura 5: Composición mineralógica de la pasta por categoría de vasija.

Figure 5: Mineralogical composition of the paste by vessel class.

características diagnósticas, pueden ser adjudicados a inosilicatos (anfíboles, piroxenos) y filosilicatos (micas) (Dorronsoro Díaz et al. 1998; Dorronsoro y Rodríguez 1998). Los mismos se registran en baja proporción en la totalidad de las muestras, aunque en algunas se distinguen especialmente como pequeños puntos heredados de la matriz.

La homogeneidad en cuanto al tamaño de las inclusiones minerales así como su abundancia, es útil para determinar si éstas fueron agregadas intencionalmente por los alfareros (PCRG 2010; Shepard 1956). En los cortes analizados, las inclusiones minerales presentan un ordenamiento equilibrado, con granos que tienden a ubicarse por lo general dentro de la fracción muy fina $(<\mathrm{I}, 125$ $\mathrm{mm})$, fina $(I, 125-0,25 \mathrm{~mm})$ y media $(0,25-0,5 \mathrm{~mm})$, sugiriendo un origen natural. Algunos cortes, por el contario, registran abundantes inclusiones minerales, particularmente de cuarzo, con una homogeneidad pobre en el tamaño de sus granos (Figura 6). Estos cortes corresponden a un recipiente liso y otro pintado de rojo (muestras I y 37 ), en cuya elaboración podrían haberse utilizado materias primas con mayor contenido de arenas. Si bien éstas pueden ser resultado de una adición intencional, la posibilidad de determinar entre inclusiones agregadas por los alfareros o naturalmente presentes en las arcillas, es uno de los aspectos más complejos de identificar (Cremonte y Bugliani 2006-09; Orton et al. 1997; PCRG 2010). Posiblemente, también pueda considerarse en este caso la hipótesis de la mixtura de dos tipos de arcillas de distinta plasticidad, tal como ha sido expuesto en los ejemplos aportados por Druc y Gwyn (1998). La realización de estudios experimentales con materias primas locales permitirá aportar datos para precisar estos aspectos.

Las inclusiones minerales registradas en los cortes se encuentran naturalmente presentes en los estratos locales, donde se ha reconocido la presencia de arenas con un predominio de cuarzo y con algunos feldespatos y minerales opacos. Se ha mencionado también la alta frecuencia de material ferruginoso, así como una superioridad general de caolinita y una presencia subordinada de montmorrillonita e illita entre las arcillas de la Formación Ituzaingó (Herbst 2000), la cual aflora en las costas del Paraná a la altura donde se localiza el sitio La Palmera 2. Dado que los óxidos de hierro funcionan como óptimos antiplásticos que equilibran la arcilla, algunos autores han propuesto la posible selección, por parte de los alfareros, de los bancos de arcilla que contenían naturalmente estos nódulos (Loponte 2008; Pérez 2010).

De todos los antiplásticos registrados, el tiesto molido es el único que puede ser considerado claramente un agregado antrópico. Se distinguen notoriamente de los grumos o pellets de arcilla 


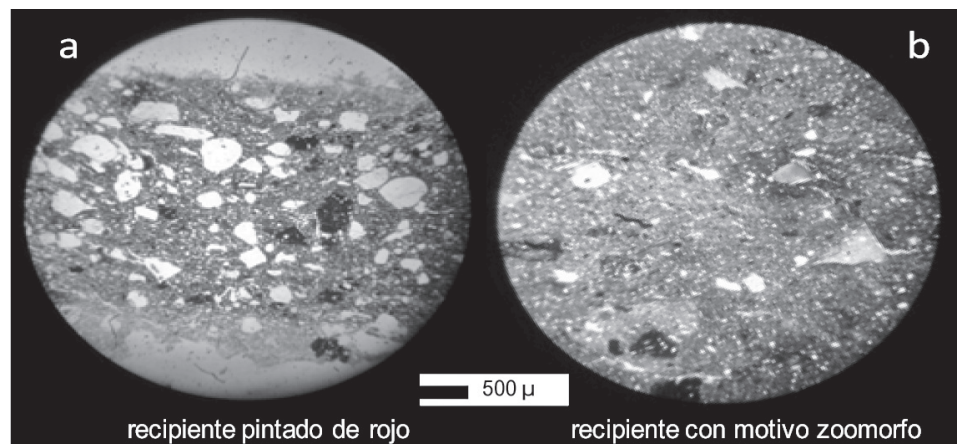

Figura 6: Ordenación de inclusiones minerales: a) pobre; b) equilibrada.

Figure 6: Sorting of mineral inclusions: a) poorly-sorted; b) well-sorted.

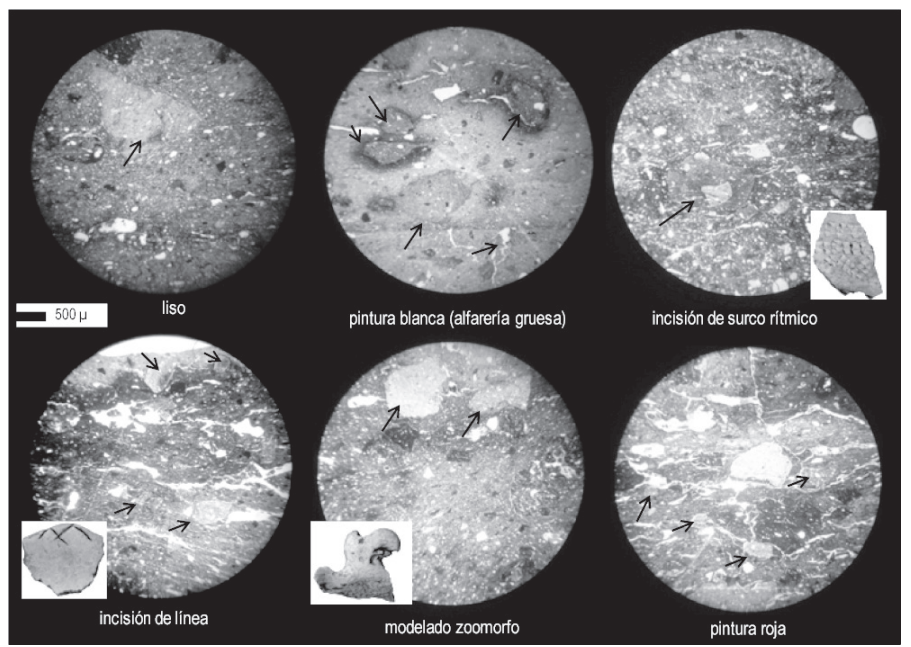

Figura 7: Inclusiones de tiesto molido: microfotografías de cortes delgados correspondientes a vasijas lisas y con diferentes decoraciones, vistas bajo nicoles paralelos.

Figure 7: Grog tempers: microphotographs of ceramic thin sections corresponding to decorated vessels and plain vessels, under parallel nicols.

por sus formas angulosas o sub-angulosas que contrastan con aquellas redondeadas y de bordes difusos propias de los grumos. También pueden ser reconocidos por su color, producto de una doble cocción, y porque la orientación de sus componentes suele diferir de aquella observada en la matriz que los aloja (Cremonte y Bugliani 2006-09; González de Bonaveri et al. 2000). Se identificaron tiestos molidos en cantidades variables en el $81 \%$ de las muestras (Tabla 2, Figura 7). Presentan dimensiones que abarcan la fracción media $(0,25-0,5 \mathrm{~mm})$, gruesa $(0,5-I \mathrm{~mm})$ y muy gruesa $(>I \mathrm{~mm})$. Se reconocen petrográficamente en los cortes correspondientes los distintos grupos artefactuales analizados. En algunas muestras son particularmente abundantes $(5$, $6,18,20,26,28,29$ y 30 , Tabla 2), donde alcanzan una frecuencia relativa del $15-30 \%$ y una frecuencia real del 5-10\%. La frecuencia relativa se refiere aquí a la proporción de tiestos molidos dentro del total de inclusiones observadas para cada muestra, en tanto que la frecuencia real está dada por la densidad de los tiestos molidos que se observan en el campo visual del microscopio. Los cortes con mayor proporción de tiesto molido están asociados a: dos vasijas lisas, una con modelado zoomorfo, dos con técnicas incisas, una con combinación de técnicas incisas y pintura roja y dos exclusivamente pintadas de rojo (Tabla I y 2). La adición de antiplásticos a la pasta cerámica es una reconocida opción tecnológica destinada a optimizar el proceso de manufactura de las vasijas, ya que tiene efectos sobre la plasticidad de la arcilla y la resistencia a las piezas cerámicas durante el secado (Rye 1981; Shepard 1956). En 
algunos ejemplos etnográficos, la adición de tiesto molido se ha vinculado particularmente también con factores simbólicos, según los cuales la incorporación de los viejos recipientes en la elaboración de las nuevas vasijas se explica como resultado de que los antepasados "...knew how to make strong pots" (Gosselain y Livingstone-Smith 2005: 9).

En escasa proporción se identifican asimismo otras inclusiones, tales como: grumos o pellets de arcilla, relleno de poros, fragmentos líticos, bioclastos: espículas de esponjas, diatomeas y restos carbonosos (Tabla 2). Éstos últimos representan restos vegetales carbonizados durante la quema de las alfarerías y mantienen un aspecto microarborescente (González de Bonaveri et al. 2000; Solá 2004). Varios autores han mencionado las desventajas de los restos carbonosos en la manufactura de vasijas destinadas a las actividades de cocción, ya que estos materiales promueven la absorción de líquidos, disminuyendo la eficacia calorífica de las alfarerías (Schiffer y Skibo 1987, 1997; Tankersley y Meinhart 1982). Su baja presencia en los cortes no sólo estaría señalando su origen natural, sino que también podría estar indicando algún proceso de purificación de la arcilla por parte de los alfareros, con el fin de extraer la mayoría de los componentes indeseados, como ha sido planteado también para las alfarerías del Delta del Paraná (Ottalagano 20I3).

\section{CONSIDERACIONES FINALES}

La búsqueda de diferencias petrográficas a singularidades estilísticas, funcionales y morfológicas de las vasijas, constituye una problemática explorada en numerosos trabajos internacionales de referencia (e.g. Betancourt et al. 1979; Peacock 197I, 1977; Riley 1981; Shepard 1942, 1965; Vaughan 1991). En Argentina, estas inquietudes han sido encauzadas ampliamente en la región Noroeste del país, donde los estudios arqueométricos cuentan con una larga y copiosa trayectoria (Baldini et al. 2005; Cremonte et al. 2003; De La Fuente et al. 2005, entre muchos otros). También se las ha abordado en la baja cuenca del Plata, en el Nordeste argentino (Frère et al. 2012; Pérez Meroni et al. 2013). En la cuenca del Paraná, específicamente, los estudios petrográficos han hecho foco particularmente en la tecnología guaraní, $y$ en sus diferencias con la de los grupos cazadores-recolectores locales (Bognanni et al. 2012; Loponte 2008; Pérez 2010; Pérez et al. 2009; Pérez y Montenegro 2009). En contextos cazadoresrecolectores, no obstante, ha faltado una discusión con respecto a la variabilidad petrográfica de las pastas cerámicas en función de la decoración de las vasijas, algo que sí se ha empezado a explorar para alfarerías guaraníes del Paraná inferior (Loponte et al. 20 I I; Pérez et al. 2009).

El análisis realizado indica una ausencia de diferencias petrográficas significativas entre los recipientes lisos y decorados de La Palmera 2. No se detectan variaciones importantes en cuanto a las características de la pasta, porosidad e inclusiones entre los recipientes lisos y los decorados con pintura roja, incisión y modelado zoomorfo, lo cual hace suponer que los alfareros aplicaron elecciones técnicas similares para la manufactura de todos estos recipientes. Esta homogeneidad petrográfica entre vasijas lisas y decoradas ha sido reconocida también para cerámicas de grupos cazadores-recolectores prehispánicos del río Salado, en la baja cuenca del Plata (Frère et al. 20I2). Asimismo, se ha podido observar similitudes petrográficas para cerámicas guaraníes con diferentes tratamientos superficiales, procedentes de contextos arqueológicos del Paraná inferior (Loponte et al. 20 I I; Pérez et al. 2009).

Los datos petrográficos refuerzan entonces los análisis macroscópicos que remarcaban la existencia de similitudes tecno-morfológicas entre recipientes con motivos incisos-zoomorfos y las vasijas lisas, en el área del Paraná medio (Ottalagano 2009). Las vasijas lisas, por no conllevar un plus de tiempo, habilidad y materiales, podrían ser consideradas como el paradigma de las vasijas domésticas. A su vez, la información petrográfica difiere, de alguna manera, con los estudios macroscópicos que señalaban particularidades especialmente morfológicas para los recipientes pintados de rojo. Su forma predominantemente abierta así como la ausencia de rastros de utilización, probablemente esté indicando un uso diferencial de estas vasijas; no obstante lo cual, el análisis petrográfico indica que en su elaboración se aplicaron pautas de manufactura común con el resto de los recipientes.

Merecen especial atención las alfarerías gruesas. Si bien estas piezas usualmente también 
presentan motivos zoomorfos, guardas incisas y/o pintura blanca, su peculiar forma carente de base $y$ de gruesas paredes las convierten en una categoría artefactual independiente. Los estudios petrográficos sugieren que los alfareros aplicaron en algunas elecciones técnicas diferentes para la confección de estos artefactos. En tal sentido, se destaca una comparativa baja proporción de inclusiones y de porosidad, así como una relativamente mayor concentración de oquedades que en las restantes categorías de vasijas consideradas. También se han identificado poros con direcciones variables, sugiriendo probablemente una técnica de fabricación diferente al del resto de las vasijas de La Palmera 2, en las cuales predomina una orientación mayormente acorde a la técnica de superposición de rodetes (Livingsonte Smith 2007; Rye 198I; Solá 2004). Estudios sobre cortes delgados de estos artefactos se han realizado asimismo en el Paraná inferior con resultados semejantes, haciendo pensar en un perfil petrográfico definido para estas piezas (Loponte 2008; Ottalagano y Pérez 20I3; Pérez 2010). Es necesario recordar que este trabajo ha tomado cortes delgados correspondientes a porciones de bordes de las vasijas. Por lo tanto, se deberá explorar a futuro si existen variaciones en la orientación de los componentes de la pasta en distintos segmentos de los recipientes, a fin de conocer si se aplicaron diferentes técnicas de manufactura en la elaboración de una misma pieza.

Las pastas analizadas mantienen cierta variabilidad en cuanto a la densidad de poros y la frecuencia de inclusiones. Sin embargo, exceptuando el caso de las alfarerías gruesas, esta variabilidad es indistinta de las categorías artefactuales consideradas. Tampoco parecen demostrar correlación con la abertura de boca de las vasijas: es decir, restringida y no restringida. Todas las pastas presentan inclusiones minerales y nódulos ferruginosos, frecuentes en los bancos sedimentarios locales. Esto, sumado al registro de masas amorfas de arcilla cocida recuperadas durante las excavaciones del sitio, apunta a pensar que la cerámica fue elaborada in situ. Si bien el porcentaje de tiestos molidos en las muestras es variable, se los identifica tanto en las cerámicas lisas como en las decoradas, representando un claro agregado antrópico.

Gran parte de los cortes analizados presenta buena proporción de poros, lo cual podría responder a la necesidad de elaborar vasijas resistentes al estrés térmico. La porosidad constituye una característica especialmente conveniente en vasijas destinadas a las actividades de cocción de alimentos.Sin embargo, una elevada frecuencia de poros puede contribuir, por el contrario, a que las vasijas pierdan su capacidad para transmitir calor (Arnold 1985; Rye 198I; Shepard 1956). La presencia de porosidad moderada en una importante cantidad de muestras, refleja tal vez la necesidad de los alfareros de manufacturar vasijas adecuadas para afrontar actividades culinarias. Puede sugerir además que los alfareros conocían las recetas técnicas más apropiadas a fin de afrontar con éxito el proceso de quema de las alfarerías, reduciendo el riesgo de potenciales fracturas ocasionadas por el estrés térmico (Shiffer y Skibo 1987).

Concluyendo, la petrografía es una técnica arqueométrica que potencializa los datos cerámicos y que no ha sido aplicada hasta el momento en materiales cerámicos del tramo medio del río Paraná. La información obtenida sugiere que las elecciones técnicas involucradas en la elaboración de recipientes lisos también se implementaron en la manufactura de los recipientes decorados, a excepción de las campanas. Esto pone de relieve la necesidad de sumar otras técnicas arqueométricas al estudio de la alfarería, así como desarrollar estudios experimentales a fin de precisar aspectos vinculados con las materias primas arcillosas utilizadas y la composición de los pigmentos empleados, una tarea que se espera concretar en la próxima etapa.

Agradecimientos: Este trabajo se realizó en el marco del proyecto PICT 2011-344 de la Agencia Nacional de Promoción Científicas y Tecnológica, Argentina.

\section{NOTAS}

La inutilidad práctica de las campanas ha dado lugar a pensar en posibles usos ceremoniales (Gaspary 1950; Serrano 1929, 1950), sin embargo no hay datos confiables que avalen esta propuesta. Debido a que algunas presentan rastros de hollín, se ha discutido también el potencial uso de estos artefactos como conservadores de rescoldo (Frenguelli 1927). Los datos distribucionales señalan que en el sector del Paraná medio entrerriano, estas piezas se asociaron tanto a contextos domésticos como funerarios (Ottalagano 2009). Actualmente, se están realizando análisis específicos para determinar la composición de los rastros de utilización que poseen algunos de estos artefactos, contribuyendo así a ampliar la información acerca de su uso. 
2 En estos estudios se consideraron las siguientes variables macroscópicas de análisis: restricción y diámetro de boca, tipo de contorno y puntos de inflexión, forma del labio, forma del cuello, grosor de pared, acabado y tratamiento de superficie, fractura, textura y color-cocción de la pasta, así como también rastros de utilización (hollín, adherencias). Para la reconstrucción de las formas se utilizaron además muestras de referencias, basadas en colecciones de vasijas completas del área del Paraná (Ottalagano 2009).

\section{BIBLIOGRAFÍA}

Adams, A., W. Mackenzie y C. Guilford. 1984. Atlas of Sedimentary Rocks under the Microscope. Logman, London.

Aguilar, J., C. Dorronsoro Fdez, J. Fernández, C. Dorronsoro Díaz, F. Martin y B. Dorronsoro. 1998. Micromorfografía de suelos. Disponible en http://www.edafologia. ugr.es/micgraf/index.htm (última consulta: |2//2//3).

Aparicio, F. 1923. "Un nuevo tipo de representaciones plásticas”. Revista de la Universidad de Buenos Aires 51:94- 106.

Arnold, D. 1985. Ceramic Theory and Cultural Process. Cambridge University Press, Cambridge.

Badano, V. M. 1946. "Sobre algunos ejemplares interesantes de representaciones plásticas". Revista de la Academia de Entre Ríos I: I I-28.

Baldini, M, M. Cremonte, I. Botto y M. Díaz. 2005. "De felinos, pastas y pigmentos. La cerámica de Choya 68 desde una perspectiva arqueométrica". En La Cultura de La Aguada y sus Expresiones Regionales, editado por S. E. Martín y M. E. Gonaldi, Pp. 87-I05. EUDELAR- SECyT-Universidad Nacional de La Rioja, La Rioja.

Balesta, B. y V. Williams. 2007. "El análisis cerámico desde 1936 hasta nuestros días". Relaciones de la Sociedad Argentina de Antropología 32: 169-190.

Balfet, H., M. F. Fauvet-Berthelot y S. Monzón. 1983. Pour la Normalisation de la Description des Poteries. Edición du Centre-National de la Recherche Scientifique, París.

Barraclough, A. 1992. "Quaternary sediment analysis: a deductive approach at A-level”. Teaching Geography 17:15-18.

Betancourt, P., T. Gaisser, E. Koss, R. Lyon, F. Matson, S. Montgomery, G. Myer y P. Swan, 1979. Vasilike Ware: an Early Bronze Age Pottery Style in Crete. SIMA, Goteborg.

Bognanni, F., M.l. Capparelli y M. Pérez. 2012. "A geoarchaeological study about the use of space in Isla Martin Garcia (Buenos Aires, Argentina)". Rosetta I I: I-28.

Caggiano, M.A.1979. Análisis y desarrollo cultural prehispánico en la cuenca inferior del Plata. Tesis para optar al grado de Doctorado en Ciencias Naturales, Facultad de Ciencias Naturales y Museo, Universidad Nacional de La Plata, La Plata.

Capdepont Caffa, I. y M. Bonomo. 20I2. "Análisis petrográfico de material cerámico del Delta del Paraná”. Anales de Arqueología y Etnología 65: |27-|47.

Carr, C. 1993. "Identifying individual vessels with $X$ radiography”. American Antiquity 58 (I): 96-II7.

Ceruti, C. 2003. "Entidades culturales presentes en la cuenca del Paraná Medio (margen entrerriana)". Mundo de Antes 3: III-I35.
Ceruti, C., O. Fontana, L. López y C. Vesco. 1980. "Arroyo Arenal 4: un hallazgo arqueológico poco común". Museo de Ciencias Naturales y Antropológicas 6: I-29.

Convención Nacional de Antropología. 1966. Primera Convención Nacional de Antropología. Universidad Nacional de Córdoba, Córdoba.

Cremonte, M.B., M. Baldini e I. Botto. 2003."Pastas y colores. Un camino al conocimiento del estilo Portezuelo de Aguada". Intersecciones en Antropología 4: 3-16.

Cremonte, M.B. y M.F. Bugliani. 2006-09. "Pasta, forma e Iconografía. Estrategias para el estudio de la cerámica arqueológica". Xama 19-23: 239-262.

De La Fuente, G., N. Kristcautzky, G. Toselli y A. Riveros. 2005. "Petrología cerámica comparativa y análisis composicional de las pinturas por MEB-EDS de estilo Aguada Portezuelo (ca.600-900 DC) en el valle de Catamarca (Noroeste Argentino)". Estudios Atacameños 30: 6I-78.

Dorronsoro, C. y R. Rodríguez. 1998. Atlas de minerales de arenas finas. Disponible en: http://www.edafologia. ugr.es/arefin/indice.htm (última consulta: I2//2/I3).

Dorronsoro Díaz, C., B. Dorronsoro Díaz, C. Dorronsoro Fdez y A. García Navarro. 1998. Mineralogía óptica. Estudio de los minerales con el microscopio petrográfico. Disponible en http://www.edafologia. ugr.es/optmine/index.htm (última consulta: I2/I2/I3).

Druc, I. y H. Gwyn. 1998. "From clay to pots: A petrographic analysis of ceramic production in the Callejón de Huaylas, North-Central Andes, Peru". Journal of Archaeological Science 25(7): 707-7।8.

Felts, W. 1942."A Petrographic examination of potsherds from Ancient Troy”.American Journal of Archaeology 46: 237-244.

Frenguelli, J. 1927. "Nuevo tipo de alfarería indígena ornitomorfa”. Boletín de Educación 24: 2-II.

Frère, M., I. González, D. Chan y M. Flores. 2012. "Petrografía de la alfarería arqueológica del río Salado Bonaerense". Comechingonia I6 (2): I I5-I37.

Gaspary, F. 1950. "Investigaciones arqueológicas y antropológicas en un "cerrito" de la isla Los Marinos (Dpto. Victoria, Entre Ríos) situada frente a Rosario". Publicaciones del Instituto de Arqueología, Lingüística y Folclore 23: 3-66.

González de Bonaveri M. I, M. M. Frére y P. Solá. 2000. "Petrografía de cerámicas arqueológicas de la cuenca del Río Salado, Provincia de Buenos Aires". Relaciones 25: 207-226.

Gibson, A. y A. Woods. 1997. Prehistoric Pottery for the Archaeologist. Leicester University Press, London.

Gosselain, O. y A. Livingstone-Smith. 2005. "The source clay selection and processing practices in Sub-Sahara Africa". En Pottery Manufacturing Process: Reconstitution and Interpretation, editado por A. Smith, D. Bosquet y R. Martineau, Pp. 33-47. BAR International Series 1359, Oxford.

Herbst, R. 2000. La Formación Ituzaingó (Plioceno). Estratigrafía y distribución. Disponible en: http://www.insugeo.org. ar/libros/cg_14/I2_la_formacion_ituzaingo.htm (última consulta: 07/II/2013).

Lechtman, H. 1977. "Style in technology.Some early thoughts". En Material Culture, Styles, Organizations, and Dynamics of Technology, editado por H. Lechtman y R. Merill, pp. 3-20. West Publishing, St. Paul. 
Lemonnier, P. 1992. Elements of an Anthropology of Technology. University of Michigan, Ann Arbor.

Letieri, F. 1998. Aspectos tecnológicos presentes en el proceso de producción cerámico del sitio Bajada Guereño y sus implicancias conductuales. Tesina para optar al grado de Licenciatura en Antropología, Facultad de Humanidades y Artes, Universidad Nacional de Rosario, Rosario.

Livingstone-Smith, A. 2007. Chaîne Opératoire de la Poterie. Musée Royal de l'Afrique Centrale, Tervuren.

Loponte, D. 2008. Arqueología del Humedal del Paraná inferior (Bajíos Ribereños Meridionales). Instituto Nacional de Antropología y Pensamiento Latinoamericano, Buenos Aires.

Loponte, D., A. Acosta, I. Capparelli y M. Pérez. 201I. "La arqueología guaraní en el extremo meridional de la Cuenca del Plata”. En Arqueología Tupi-guaraní, editado por D. Loponte y A.Acosta, Pp. I I I-I 54. INAPL, Buenos Aires.

Lothrop, S. 1932. "Indians of the Paraná Delta River". Annals of the New York Academy of Science 23: 77-232.

Mathew, A., J. Wood, y C. Oliver. 1991. "Spots before your eyes: new comparison charts for visual percentage estimation in archaeological materials". En Recent Developments in Ceramic Petrology, editado porA. Middleton y I. Freestone, Pp. 2 I I263. British Museum Occasional Paper 8I, London.

Orton, C., P. Tyers y A. Vince.1997. La Cerámica en Arqueología. Crítica, Barcelona.

Ottalagano, F. 2009. Aproximaciones al simbolismo de los grupos cazadores-recolectores de las Tierras Bajas del Paraná: un abordaje contextual del arte mobiliar cerámico. Tesis para optar por el grado de Doctorado en Humanidades y Artes, Mención Antropología, Facultad de Humanidades y Artes, Universidad Nacional de Rosario, Rosario.

----2013. "The pre-Hispanic ceramic technology of South American hunter-gatherers (Paraná River Delta, Argentina): a preliminary archaeometric study". Archaeological and Anthropological Sciences 5: 59-68.

----20I4. "El estudio de la variabilidad cerámica: conceptos teóricos y praxis arqueológica en las tierras bajas del río Paraná". Revista Arqueología, en prensa.

Ottalagano, F., M. Darigo, B. Pereyra, C. Brancatelli, L. Iannelli y D. Loponte. 2013. Nuevos datos para la arqueología del Paraná medio: investigaciones arqueológicas en el sitio La Palmera 2 (provincia de Entre Ríos). Manuscrito en posesión de los autores..

Ottalagano, F. y M. Pérez. 2013. "Estudios petrográficos comparativos: un acercamiento regional a la tecnología cerámica del Delta del Paraná”. Cuadernos del INAPL, Series Especiales I (2): 79-94.

Outes, F. 1918.“Nuevo jalón septentrional en la dispersión de representaciones plásticas en la cuenca paranaense y su valor indicador". Anales de la Sociedad Científica Argentina 85: 53-66.

Peacock, D. 197I."Petrography of certain coarse pottery". En Excavations at Fishbourne, editado porB. Cunliffe, Pp. 255-259. Society of Antiquaries, London.

----1977. "Roman amphorae: typology, fabric and origins". Collection de l'Ecole Françoise de Rome 32, 26I-273.

Pérez, M. 20I0. Tecnología de producción de la alfarería durante el Holoceno tardío en el humedal del Paraná inferior. Un estudio petrográfico.
Tesis para optar al grado de Licenciada en Ciencias Antropológicas. Facultad de Filosofía y Letras, Universidad de Buenos Aires.

Pérez, M., I. Capparelli, D. Loponte, T. Montenegro y N. Russo.2009. "Estudo petrográfico da tecnologia cerâmica guarani no extremo sul de sua distribução: rio Paraná inferior e estuário do Rio da Prata, Argentina”. Revista de Arqueología 22: 65-82.

Pérez, M. y T. Montenegro. 2009. "Análisis petrográfico en alfarería del norte de la provincia de Buenos Aires". En Problemáticas de la Arqueología Contemporánea (Tomo III), editado por A.Austral y M.Tamagnini, Pp. 565-573. Universidad Nacional de Río Cuarto, Córdoba.

Pérez Meroni, M., M.C. Paleo, L. Lópezy N. Ghiani Etchenique. 20I3. "Caracterización de pastas cerámicas del sitio Las Marías, Partido de Magdalena, provincia de Buenos Aires. Integración de distintas líneas de trabajo". Cuadernos del INAPL- Series Especiales I (2): 95-106.

Peterson, S. 2009 Thin-section Petrography of Ceramic Materials. INSTAP Academic Press, Philadelphia.

Pierret, A. 1994. "Identification des techniques de façonnage: intérêt des données expérimentales pour l'analyse des microstructures". En Terre Cuite et Société la Céramique, Document Technique, Economique, editado por D. Binder y J. Courtin, Pp. 7591. Éditions APDCA, Juan-les-Pins.

Prehistoric Ceramic Research Group (PCRG). 2010. The study of later prehistoric pottery: general policies and guidelines for analysis and publication. Occasional Paper I-2 Publishing PCRG. http://www.pcrg.org.uk/PublicationsI-2.htm. (Última consulta: 04/05/2012).

Rice, P. 1987. Pottery Analysis: a Sourcebook. University of Chicago Press, Chicago.

---1996. "Recent ceramic analysis.Function, style and origins”.Journal of Archaeological Research 4(2): I33-161.

Riley, J. 198I. "Petrological examination of coarse-ware Stirrup-Jars from Mycenae". The Annual of the British School at Athens 76: 335-340.

Rye, O. 1981.Pottery Technology. Taraxacum, Washington.

Sackett, J. 1985. "Style, ethnicity and stone tools". En Status, Structure an Stratification: Current Archaeological Reconstructions, editado por R. Thomson, M. García y F. Kense, Pp. 277-282. University of Calgary, Calgary.

Schiffer, M. y J. Skibo. 1987. "Theory and experiment in the study of technological change". Current Antropology 28 (5): 595-621.

----1997. "The explanation of artifact variability".American Antiquity 62 (I): 27-50.

Schmitz, P., C. Ceruti, A. González y A. Rizzo. 1972. "Investigaciones arqueológicas en la zona de Goya (Corrientes), Argentina”. Dédalo 8 (I5): II-I2I.

Serrano, A. 1929. "El área de dispersión de las llamadas alfarerías gruesas del territorio argentino”. Physis 10: I-9.

----1950. Los primitivos Habitantes de Entre Ríos. Ministerio de Educación, Paraná.

----1958. Manual de la Cerámica Indígena. Editorial Assandri, Córdoba. 
Shepard, A. 1942. Río Grande Glaze Paint Ware: a Study Illustrating the Place of Ceramic Technological Analysis in Archaeological Research. Carnegie Institution of Washington, Washington D.C.

---- 1956. Ceramics for the Archaeologist. Carnegie Institution of Washington, Washington.

----1965. "Río Grande glaze-paint pottery: a test of petrographic analysis". En Ceramics and Man, editado por F. Matson, Pp. 62-87. Aladine Publishing, Chicago.

Skibo J. 20I3. Understanding Pottery Function.Springer, New York-Heidelberg.

Solá, P. 2004. Las arcillas y el análisis petrológico de cerámica arqueológica. Apunte para la Cátedra Ergología y Tecnología de la Carrera de Ciencias Antropológicas, Orientación Arqueología, UBA. Manuscrito en posesión del autor.

Tankersley, K. y J. Meinhart.1982. "Physical and structural properties of ceramic materials utilized by a fort ancient group". Midcontinental Journal of Archaeology 7: 225-243.

Torres, L. M. 1903. “Los cementerios indígenas del sur de Entre Ríos y su relación con los de Uruguay, túmulos de Campana (Bs. As.) y Santos (Brasil)". Anales del Museo Nacional de Buenos Aires 9 (2): 57-75.

---1911. "El totemismo. Su origen, significado y supervivencias". Anales del Museo de Buenos Aires 20: 485-553.

Vaughan, S. 1991."Late Cypriot base ring ware: studies in raw materials and technology”. En Recent Developments in Ceramic Petrology, editado por A. Middleton y I. Freestone, Pp. 337-368. BMOP 8I, London.

Whitbread, I. 1996. "Detection and interpretation on preferred orientation in ceramic thin-sections". En Imaging the Past, editado por T. Higgins, P. Maine y J. Long, Pp. I73-I8I. Occasional Paper-British Museum II4, London.

Woods, A. 1985."An introductory note and the use of tangential thin sections for distinguishing between wheel-thrown and coil-ring-built vessels". Bulletin of the Experimental Firing Group 3:100-II4.

Zeballos, E. y P. Pico. 1878. "Informe sobre el túmulo prehistórico de Campana”. Anales de la Sociedad Científica Argentina 6: $244-260$ 